\title{
Mosaicos de uma trajetória acadêmica: homenagem a nosso querido professor Cleiton de Oliveira
}

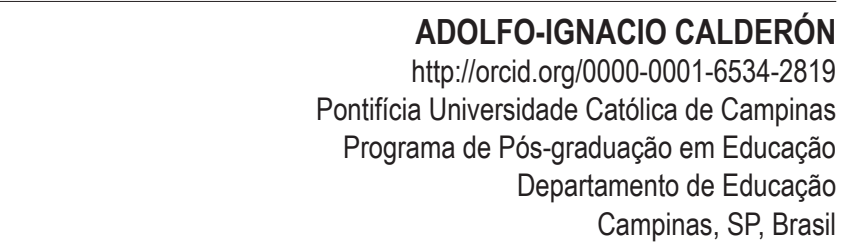

RAFAEL FERNANDO DA COSTA https://orcid.org/0000-0002-2757-1036

Pontifícia Universidade Católica de Campinas

Programa de Pós-graduação em Educação Linha de Pesquisa de Formação de Professores e Práticas Pedagógicas

Campinas, SP, Brasil

MARCO WANDERCIL

https://orcid.org/0000-0002-9295-1051

Pontifícia Universidade Católica de Campinas

Programa de Pós-graduação em Educação Grupo de Avaliação, Políticas e Sistemas Educacionais

Campinas, SP, Brasil

\author{
Alheias e nossas as palavras voam. \\ Bando de borboletas multicores, as palavras voam \\ Bando azul de andorinhas, bando de gaivotas brancas, \\ as palavras voam. \\ Viam as palavras como águias imensas. \\ Como escuros morcegos como negros abutres, \\ as palavras voam. \\ Ob! Alto e baixo em círculos e retas acima de nós, \\ em redor de nós, as palavras voam. \\ $E$ às vezes pousam. \\ Voo-Cecilia Meireles
}

Concordando com a belíssima poesia Voo de Cecília Meireles, sem dúvida alguma, o poder das palavras é imensurável, se espalham como as sementes do dente-de-leão na velocidade do vento, sem saber onde pousaram ou se pousarão.

A partida do nosso querido professor Cleiton de Oliveira, aos 76 anos de idade, em 12 de maio de 2021, deixa saudades nos corações de todos aqueles que conviveram com ele, o amavam, o respeitavam e o admiravam. Suas palavras foram ouvidas por centenas de alunos de todos os níveis de ensino, por pesquisadores, autoridades públicas e também classe política, dentro das inúmeras atividades 
desenvolvidas pelo professor Cleiton ao longo de sua trajetória, dentre das quais destacam-se: professor de educação básica da rede estadual de São Paulo; docente universitário em diversas instituições estatais e do setor privado, tais como: Universidade Estadual de Campinas (UNICAMP), na Universidade Metodista de Piracicaba (UNIMEP), Salesianos de Americana (São Paulo) e Universidade de Sorocaba (UNISO); Secretário Municipal de Educação do município de Santa Bárbara D’Oeste (São Paulo); conselheiro suplente e titular do Conselho Estadual de Educação de São Paulo; membro fundador da União dos Dirigentes Municipais de Educação (UNDIME); diretor da Associação Nacional de Política e Administração da Educação (ANPAE) - São Paulo, entre outras atividades.

Como as sementes de dente-de-leão, suas palavras voaram e, muitas delas, certamente caíram em terreno fértil, marcando a vida e os processos formativos de muitas pessoas, dentre elas 37 Mestres e 20 Doutores. Entretanto, como diz o provérbio romano Verba volant, scripta manent, as palavras voam, os escritos permanecem. Nesse sentido, considerando a permanência da escrita, preparamos este documento em forma de entrevista, para que as palavras do nosso saudoso professor Cleiton de Oliveira permaneçam eternizadas e possam voar no mundo digital.

Tudo aconteceu em março de 2016, quando o primeiro autor deste manuscrito, tinha recebido a incumbência de ministrar a disciplina obrigatória, que tinha por nome "A produção do conhecimento no campo das Ciências da Educação", para a primeira turma do recém-inaugurado Doutorado em Educação do Programa de Pós-Graduação em Educação da Pontifícia Universidade Católica de Campinas.

O objetivo dessa disciplina era compreender, panoramicamente, a forma de produção, disseminação e avaliação do conhecimento científico no âmbito educacional, enquanto seara dos pesquisadores que obtém formação doutoral em Educação. Para atingir esse objetivo foram utilizadas diversas estratégias de aprendizagem, sendo uma delas, e talvez a mais importante, o projeto "Vivências e percursos formativos em nível de doutorado: encontro com formadores de formadores", idealizado e coordenado pelo Prof. Dr. Adolfo Ignacio Calderón. Este projeto tinha como objetivo possibilitar aos doutorandos aprender a partir das palavras, das vivências e das experiências de grandes intelectuais brasileiros que, ao longo de sua trajetória, além de terem realizado relevantes contribuições ao campo da Ciências da Educação, formaram doutores que foram ganhando destaque em nível nacional no âmbito da produção do conhecimento na área de educação. 
Para compartilhar suas experiências, no projeto em questão, foram convidados quatro queridos e grandes intelectuais brasileiros, os quais, generosamente não tiveram dúvidas em aceitar o convite para participar do projeto. São eles: o Dr. Cleiton de Oliveira, professor aposentado da UNICAMP e da UNIMEP; o Dr. Valdemar Sguissardi, professor titular aposentado da Universidade Federal de São Carlos (UFSCar) e da UNIMEP; a Dra. Lídia Maria Rodrigo, professora do PPGE da UNICAMP e, finalmente, o Dr. Newton Cesar Balzan, QEPD, bolsista produtividade em pesquisa do CNPq (Sênior), professor aposentado da UNICAMP e da PUC-Campinas.

Convém destacar que, entre outras contribuições ao campo da Ciências da Educação, os quatro convidados se caracterizam por serem formadores de formadores, de pesquisadores e cientistas na área de educação. Por exemplo, o Dr. Cleiton de Oliveira, entre outros intelectuais, formou ao Dr. Pedro Ganzeli, professor do PPGE da UNICAMP; o Dr. Valdemar Sguissardi, formou, ao Dr. José Carlos Rothen, professor do PPGE da UFSCar e ao Dr. Nelson Cardoso Amaral, professor aposentado da Universidade Federal de Goiás, entre outros; a Dra. Lidia Maria Rodrigo, formou ao Dr. Samuel Mendonça, professor e excoordenador do PPGE da Pontifícia Universidade Católica de Campinas (PUCCAMPINAS); o saudoso Dr. Newton Cesar Balzan, dentre outros, foi orientador em nível de mestrado e doutorado do nosso homenageado, nosso eterno amigo e professor Cleiton, bem como outros grandes intelectuais, como a pesquisadora Dra. Sonia Giubilei, também professora aposentada da UNICAMP.

O projeto "Vivências e percursos formativos em nível de doutorado: encontro com formadores de formadores", foi realizado com a presença dos quatro pesquisadores citados, no dia 21 de março de 2016, às 9h30 da manhã, nas instalações do Centro de Ciências Humanas e Sociais Aplicadas da PUC-Campinas (Campus I), com a presença de nove doutorandos e mediadas pelo coordenador do projeto. Cada convidado recebeu uma lista de perguntas sobre seus processos formativos que lhes serviu como roteiro orientador de sua intervenção.

As experiências compartilhadas pelo professor Cleiton de Oliveira foram sistematizadas neste texto, na forma de entrevista, com suas palavras transcritas de forma integral, com pequenos ajustes para deixar os discursos mais claros e coerentes para o leitor. Foi um momento rico de aprendizado que ultrapassa os muros da sala de aula e hoje chega aos leitores da Revista Brasileira de Política e Administração da Educação.

A voz do professor Cleiton de Oliveira nos apresenta, como um mosaico, a sua trajetória acadêmica e, nessa, podemos perceber o quanto a vida pessoal se entrelaça, sendo ao mesmo tempo base para a profissão acadêmica e produto desta profissão. $\mathrm{Na}$ fala do professor são os "acasos da vida" que devem ser 
aproveitados com muita coragem e empenho. Nos chama atenção o modo como o professor foi construindo a sua história e a importância dos encontros, da parceria e do reconhecimento. Ser professor, não era em princípio seu desejo, mas tornou-se! Sua vida e sua docência são inspiradoras e portadoras do mais alto nível de excelência.

A sua palavra nos relembra da importância do reconhecimento da profissão docente, do trabalho docente, inclusive o reconhecimento social que gera orgulho e contribui para o desenvolvimento da profissão e do profissional. Tal reconhecimento na atualidade está desgastado e, ser professor - mesmo efetivo e/ou concursado - já não carrega esse prestígio, o que atenua a profissão, o trabalho docente e o próprio sujeito professor.

A trajetória do professor Cleiton mostra o seu processo de doutoramento e as dificuldades na pesquisa, relembra aos mestrandos e doutorandos que suas angústias, também são vivenciadas até por grandes doutores. O cotidiano da pesquisa científica é composto por agruras e prazeres. Formar-se doutor é ter o compromisso de enxergar a realidade com clareza e, a partir do rigor científico, cumprir a função social da pesquisa, apontando caminhos de superação qualitativa. O doutoramento traz exigências e responsabilidades, não é um caminho fácil, mas é possível e necessário.

A publicação da fala do professor Cleiton de Oliveira possibilita-nos o acesso ao percurso de uma vida acadêmica de vocação, totalmente dedicada ao ensino generoso e à pesquisa séria e rigorosa. O mosaico apresentado pelo querido professor Cleiton com sua honestidade acadêmica, nos leva a pensar o processo formativo dos doutores no nosso país e refletir sobre a produção do conhecimento e do compromisso dos doutores em educação em formar novos doutores.

Além da contribuição filosófica e conceitual que o saudoso professor Cleiton de Oliveira nos deixou, temos nessa entrevista o aspecto humano do professor, conhecer sua narrativa tornou-se um privilégio que não deve ser restrito a um grupo de doutorandos em Educação da PUC-Campinas, mas acessível a todos, para servir de material de reflexão e inspiração de caminhada. Daí a vontade de tornar pública, nesta conceituada revista, as palavras do Professor Doutor Cleiton de Oliveira na forma de entrevista, a mesma que se complementa com uma outra entrevista por ele concedida, em 2014, aos professores Bruno Pucci, Cesar Romero Amaral Vieira, e Maria Nazaré da Cruz, publicada na Revista Comunicações, ano 22, n. 2, 2015. 


\section{Para iniciar, fale-nos sobre o seu início profissional, como se deu a escolha por ser professor?}

Professor Cleiton de Oliveira: Agradeço muito a possibilidade de estar aqui hoje com vocês. Eu acho que muita coisa acontece por acaso, porém, além disso, há algo racional e você tem que estar preparado para aproveitar a chance que esse acaso ocasiona e ter coragem. Eu passei por vários acasos. Fiz escola Normal ${ }^{1}$, uma formação que era considerada para os pobres, vista assim pela sociedade, mas que dava uma profissão. E, meu pai reafirmou: "tem que ter uma profissão na vida, vai ser professor primário”! Por pouco que ganhasse, era algo palpável, mas eu queria fazer científico, eu gostava de matemática, dava aula particular de matemática, no entanto, fui lá fazer o Normal. Não queria ser professor. Fui trabalhar em um escritório, em três meses descobri que eu queria tudo na vida, menos permanecer naquele escritório no qual estava [risos]. $\mathrm{Na}$ época, aconteceu algo inédito no estado de São Paulo: a realização de concurso de provas e títulos para professor. Até então, no estado de São Paulo, havia apenas concursos de títulos. A pessoa era professor substituto na escola e dava aulas quando faltava o professor titular e isso contava pontos, pois até então, os pontos eram somados e assim o substituto se tornava titular, estrutura de ingresso vigente há mais de 100 anos. O primeiro concurso com provas se deu em 1963! Prestei esse concurso, fui aprovado. Só que era provas e títulos, eu não tinha pontos, pois nunca havia dado aulas, então fiquei lá embaixo na relação.

Como a rede (de ensino) era predominantemente estadual, havia uma única lista de vagas e de candidatos para o estado todo. Quando eu entrei, outras 15000 (quinze mil) pessoas se tornaram efetivas na rede de ensino. Havia uma outra lei 'supimpa', conhecida como lei do quinto, a cada quatro mulheres que escolhessem vagas em um grupo escolar (escola), o quinto tinha que um ser homem. Porque estava ficando feminina a profissão. Eles imaginavam que se facilitasse o ingresso, ela se tornaria masculina. A professora Zeila Demartini², posteriormente, fez vários estudos que mostravam que na verdade, expressão dela: "era uma profissão feminina e uma carreira masculina". Ou seja, os homens se tornavam diretores, supervisores e iam embora. Para aproveitar ainda o quinto, nós pegávamos escolas chamadas masculinas, elas eram mistas, mas eram escolas de difícil acesso e lá fui eu, me tornei aos 20 anos de idade, efetivo. Tem que usar a

1 Escola Normal e/ou Curso Normal era um curso público de nível secundário (hoje ensino médio) para formação de professores para atuarem no magistério do ensino primário, com a LDB 9394 de 1996 a formação de educadores passou a ocorrer em cursos de graduação licenciatura plena do ensino superior.

2 Prof. ${ }^{a}$ Dr. $^{a}$ Zeila de Brito Fabri Demartini. Atualmente é Pesquisadora $1 \mathrm{C}$ e consultora ad hoc do Conselho Nacional de Desenvolvimento Científico e Tecnológico, professora doutora da Universidade Metodista de São Paulo e diretora de pesquisa do Centro de Estudos Rurais e Urbanos.

1116 - Rev. Bras. Polít. Adm. Educ. - v. 37, n. 2, p. 1112 - 1124, jan./ago. 2021 
expressão "escolhi cadeira". Isso era algo espantoso. Porque era uma "corruptela" do catedrático, o professor catedrático, que tinha cadeira. Eu me lembro que a escolha se deu em um grupo escolar de São Paulo que ficava na Consolação e eu descia de lá para ir para a rodoviária. Eu não me continha e falava para mim mesmo: "será que essas pessoas que estão passando por mim, sabem que eu me tornei efetivo no estado de São Paulo?!" [risos]. Isso para um professor, era o máximo, ser efetivo! Eu ficava a semana toda na escola, no município de São Paulo e vinha para minha cidade no final de semana. Eu ia no barbeiro e, quando entrava, ele falava para os fregueses: "Esse é o professor". Eu ficava vermelho, porque tinha só 20 anos.

\section{O senhor iniciou sua formação docente na Escola Normal e já começou a atuar. Como foi o ingresso no ensino superior?}

Professor Cleiton de Oliveira: São várias emoções! Como professor, lecionei em várias cidades, Oriente, Socorro, Americana, Santa Bárbara D’Oeste. $\mathrm{Na}$ escola normal havia um curso para diretores de escola, de Administração Escolar, era escola de ensino médio, 'o professor Balzan, não gosta muito desse termo'. Enfim, fiz esse curso que durava cerca de dois anos e, nessa época, algumas faculdades começaram a aceitar alunos desse curso, dando equivalência para algumas disciplinas e com isso fui classificado para um curso de Pedagogia no interior do Estado. Eu vim para Piracicaba porque o curso era à noite, um dos poucos cursos noturnos do interior. Então, fiz a Pedagogia, aproveitando algumas disciplinas, cursando outras, mas era um curso muito inicial e de todos os professores nossos na graduação, apenas uma fazia mestrado. Os demais eram diretores experientes, inspetores experientes e na verdade eles trabalhavam com a prática e não com a teoria. A professora que fazia o mestrado era a professora Maria Lúcia Hilsdorf ${ }^{3}$, ela deu aula em Araraquara e se aposentou na USP. A tese dela foi sobre o piracicabano, na UNIMEP.

$\mathrm{Na}$ época em que eu fazia pedagogia, aconteceu um outro fato, houve uma alteração nos cursos - o período que o Saviani chama de tecnicista -, o parecer 252 de $1969^{4}$ que criou habilitações. Até então, era o pedagogo, a partir

\footnotetext{
3 Prof. ${ }^{a}$ Dr. ${ }^{a}$ Maria Lucia Spedo Hilsdorf. Atualmente é professora aposentada da Universidade de São Paulo.

4 BRASIL. Conselho Federal de Educação. Parecer n 252/69. Fixa os mínimos de conteúdo e duração a serem observados na organização do curso de Pedagogia. Relator: Valnir Chagas. In: Documenta. $\mathrm{n}^{\circ}$ 100. Abr. 1969.
} 
daí você era ou administrador escolar, ou supervisor, ou orientador educacional, planejador, e por aí vai. A UNIMEP já colocou em prática isso e já saímos com pareceres, com apostilas no verso do diploma com essas habilitações.

\section{Como o senhor iniciou a docência no ensino superior?}

Professor Cleiton de Oliveira: Na época a UNIMEP tinha a pretensão de se tornar universidade. Eu estava nesses encontros com eles, foi aí que percebi: "Eu quero ser professor de ensino superior". Era algo que nem tinha me passado pela cabeça antes. Surgiram duas aulas de didática e eu planejava a semana inteira aquelas duas aulas. Sabia tudo o que poderia acontecer, tentava prever, mas a realidade sempre traz novidades.

Comecei a fazer o mestrado e, naquele tempo, não existiam prazos, tanto é que meu mestrado foi longo, porque eu trabalhava em duas ou três escolas e ao mesmo tempo estava me adaptando ao mestrado. Eu estudava como um 'louco' e quando chegava na aula, as observações que o professor fazia e que alguns alunos faziam, era algo que não tinha sequer passado pela minha cabeça. Isso se deve à formação da graduação, por uma formação estritamente prática na qual a teoria não era abordada. Eu falava, 'mas eu preciso aprender'. Gastava dois minutos e meio por página que eu lia com anotações, tudo era marcado, porque isso era lido no intervalo das aulas, era lido à noite quando voltava da escola, no sábado e domingo.

No mestrado, já de cara, meu primeiro professor foi o Demerval Saviani e ele terminava o curso com uma entrevista e falou para mim: "que nota você merece?" Eu falei: "mereço a menor nota com que se aprove. Eu não posso ser reprovado, porque me esforcei, mas não mereço mais do que o mínimo". Eu acho que ele pensou a mesma coisa, pois me deu sete [risos]. Com o passar do tempo você vai "pegando a embocadura", vai aprendendo, lendo, estudando e eram muitas disciplinas, muito mais do que hoje. Só sei que a última disciplina fiz com o Demerval de novo e obtive a maior nota da turma. Eu aprendi a estudar, a ver o que era importante no texto, o que não era, o que era secundário, onde estavam as raízes de tudo.

Como a UNIMEP era o primeiro curso do interior de pós-graduação e tinha o corpo próprio de professores, tinha os que vinham da PUC de São Paulo e os da UNICAMP. Dentre estes professores tinha o professor Charles ${ }^{5} \mathrm{da}$ UNICAMP, ele pediu que eu lhe entregasse um programa de ensino da disciplina "Estrutura e Funcionamento de Ensino" que era o que ele trabalhava. Eu observava 
o seguinte, essa disciplina para alguns era apenas legislação, para outros era só história da educação e eu imaginava como poder trabalhar essa disciplina com o conteúdo, tendo a lei como referência, mas examinando a situação econômica, social e política, como ela foi produzida. Foi assim que eu montei o programa e entreguei para ele. Perguntei ao professor Charles para que era aquele material e ele disse que não poderia me contar, pensei comigo, ‘tem coisa aí!'. Meses depois ele disse que havia pedido para várias pessoas e, o departamento da UNICAMP se reuniu e eu fui contratado dessa maneira. Esse era o concurso daquela época e fui para a UNICAMP.

$\mathrm{Na}$ UNICAMP, Doutor Newton Balzan era coordenador das licenciaturas e eu representava a minha disciplina, ou algo assim, só sei que tínhamos reuniões e nos encontrávamos. Eu já havia terminado as disciplinas do mestrado e pedi a ele que me orientasse. Eu fiz minha dissertação sobre a UNIMEP, examinando duas administrações, uma mercadológica e a outra que veio a seguir, em função do rompimento que houve na igreja metodista, entre o modelo trazido por missionários norte-americanos e algo, vamos chamar aqui por enquanto, de brasilidade que eles tinham, eu fazia o contraponto entre essas duas administrações. Esse foi um período extremamente rico, porque saia de um ponto e se encaminhava para outro, lógico que houve entreveiros pelo caminho, mas foi uma mudança muito grande. Esse trabalho foi retomado agora (2016) devido a comemoração de 50 anos do curso de Pedagogia da UNIMEP.

\section{Como foi seu ingresso no curso de doutorado e como foi seu processo de doutoramento?}

Professor Cleiton de Oliveira: Após conclusão do mestrado, comecei a cursar disciplinas do doutorado na UNICAMP. Então, posso dizer que fiz mestrado onde havia mestrado e onde no momento eu trabalhava. Já o doutorado fiz também onde havia doutorado e porque eu já estava, a época, na UNICAMP. E nesse meio tempo, eu fui Secretário de Educação de Santa Bárbara D’Oeste. Um amigo meu de infância se tornou prefeito e me convidou, eu aceitei e lá fui ser Secretário de Educação. Tanto em Piracicaba, quanto como Secretário, sempre guardei ofícios, dados, circulares, fiquei lá por seis anos, durante o mandato desse meu amigo. Minha gestão foi de 1983 a 1988, período de grande mudança, de abertura, de descentralização, que tinha de fato por traz, por um lado o modelo neoliberal de descentralização, mas havia também um outro lado, e isso eu exploro bem na tese. A descentralização era muito forte no Brasil, desde o século XIX, 
ou seja, desde 1835 pelo Ato Adicional ${ }^{6}$, quando o Poder Central guarda para si algumas atividades e deixa outras para os demais entes, dentre elas a educação. É por isso que a questão da municipalização do ensino é muito forte em São Paulo, e Minas Gerais e não é no Rio Grande do Sul nem no Nordeste, porque lá já existiam escolas municipais há muito tempo. Nós trabalhamos com lei orgânica única para o estado todo até 1988. No Rio Grande do Sul não, eles tinham as chamadas cartas brancas, já após a Proclamação da República, cada município poderia criar a sua própria carta. É interessante essa riqueza que é o Brasil, como a lei possibilita que cada região, que cada estado (província) molde suas redes. Por isso que a rede estadual paulista sempre foi muito forte, foi um padrão e quando começa a municipalização mais recente, do governo Montoro ${ }^{7}$ para cá, ainda assim a rede estadual é forte. Os secretários de educação, em geral, passaram pela rede estadual, salvo Campinas, que tem uma rede (municipal) bem antiga, mas em toda a região, tudo é novo, a região toda, não tinha escolas municipais. Como guardei todo esse material, eu fiz minha pesquisa e escrevi minha tese de doutorado sobre a municipalização de ensino de 1983 a 1988 no governo Montoro. Depois disso veio o FUNDEF (Fundo de Manutenção e Desenvolvimento do Ensino Fundamental e de Valorização do Magistério), depois o FUNDEB (Fundo de Manutenção e Desenvolvimento da Educação Básica e de Valorização dos Profissionais da Educação), esse financiamento da educação e a municipalização virou uma realidade no país e tornou-se um assunto muito presente. Então, aquilo que eu estudei no doutorado, tornou-se uma questão de ordem do dia. Eu tive o prazer de orientar uma aluna que estudou a municipalização do ensino em Goiás, outra estudou em Minas Gerais, uma terceira estudou no Rio de Janeiro e, um quarto aluno estudou uma região do Paraná. Embora o fenômeno seja o mesmo, ele se manifestou e ocorreu com feições locais e suas especificidades. O professor doutor Newton me orientou também no doutorado, me acompanhou.

\section{O professor doutor Newton Cesar Balzan lhe orientou então no mestrado e no doutorado. Como você avalia essa relação e o que tem para nos contar sobre o professor Newton?}

Professor Cleiton de Oliveira: Foi muito bom, tanto que eu pedi "bis". Enfatizo as qualidades do meu orientador, exigente quanto à redação, quanto ao material final. Eu sempre me identifiquei muito com o doutor Newton e eu nunca tive problema, nunca tivemos uma discussão, nada disso, pelo contrário, nós

\footnotetext{
6 O Ato Adicional, alterou a Constituição de 1824 e ampliou a dimensão das reformas liberais até então empreendidas. 
conversamos, até hoje, no mínimo uma vez por mês, eu telefono ou ele telefona, as coisas se encaminham muito bem. Já o convidei para bancas minhas, em geral, nosso orientando nos convida para a primeira banca, eu acho tão legal isso. Outro dia eu estava tomando um café na UNICAMP, um rapaz me deixou passar na frente e tomar o café antes. Ele perguntou meu nome e eu falei. Ele me disse: "Ah! O senhor foi orientador do meu orientador", Prof. José Vaidergorn ${ }^{8}$. Falei assim: "então, eu sou seu avô" [risos].

No doutoramento, as minhas dificuldades foram as análises políticas, em relação à metodologia. Recentemente, têm surgido mais trabalhos nessa linha de análise de políticas públicas, autores mais recentes, como a professora Isaura Belloni ${ }^{9}$. Contudo, no período em que fiz doutorado, era um pessoal americano que trabalhava uma visão já superada. Eu e o doutor Newton enfrentamos essa dificuldade, nós fomos fazendo, como deve ser feita, desbravando o caminho, olhando o contexto, as razões, porque que surgiu, o que afeta e acarreta. Agora se fosse para refazer, eu faria tudo com mais propriedade, mas a tese é datada, assim como o mestrado é datado, você faz com o que você tem, com o recurso que você tem. Eu vejo que, no Brasil, essa questão da metodologia se desenvolveu muito, dos últimos anos para cá, nos últimos dez anos, tanto é que de suas implicações, temos essa coleção sobre metodologia ${ }^{10}$ que não existia antes, deu um trabalhão fazer tudo isso [mostrando o volume da coleção].

\section{Após o término do doutorado qual foi o caminho percorrido?}

Professor Cleiton de Oliveira: Bom, o que me acarretou... eu, terminado o doutorado, me candidatei e fui coordenador das licenciaturas na UNICAMP, seguindo o orientador ${ }^{11}$, por dois anos e meio. Depois me aposentei, achei que ia parar. Fui convidado para dar uma assessoria na secretaria de educação de estado de São Paulo. Venceu o primeiro contrato e eu deixei o cargo, porque a Rose $^{12}$ era a secretária e ela queria municipalizar de forma dura, diferente do que eu pensava, não é esse o princípio e não é assim que se faz. Eu saí, o mais breve possível. Conosco era a questão da reorganização do ensino, usava-se como disfarce separar crianças de adolescentes, mas na verdade queríamos reorganizar o ensino, agora voltou essa questão novamente, isso é como 'canções e epidemias'

$8 \quad$ Professor aposentado da UNICAMP.

$9 \quad$ Professora da Universidade de Brasília

10 Coleção "Série Pesquisa" da editora Liber Livro, primeiro volume 2010, sequência de trabalhos que tratam de aspectos diferenciados relativos ao desenvolvimento de pesquisas na área educacional.

11 Referia-se a seguir os passos de seu orientador, que também tinha desempenhado esse cargo.

12 Rose Neubauer, Secretária Estadual da Educação entre janeiro de 1995 e abril de 2002. 
vão e voltam. Depois de sair, fui dar aula em Sorocaba, fiquei seis meses na UNISO, fui trabalhar com o professor Wilson Sandano ${ }^{13}$ que foi meu colega no mestrado. Estando ali, a UNIMEP abriu concurso. João dos Reis ${ }^{14}$ havia saído da UNIMEP, eu me candidatei e fui aprovado. Foi um clima muito diferente do que eu estava acostumado. Na UNICAMP, no meu tempo, até começo de 1990, era cada professor por si, preocupado com a sua pesquisa, não havia essa grande preocupação com a publicação. Na UNIMEP era um grupo bem pequeno, erámos uns 15 ou 16 professores e havia um dinamismo, uma participação. Quando alguém sabia de algum evento, aquilo já era duplicado, já era conversado, tudo era discutido. Quando começou as mudanças na avaliação da CAPES e a ideia de escrever se tornou algo presente, o programa já realizava, já tinha isso muito presente no seu DNA, isso foi uma maravilha. Foi um período muito rico, de participação em eventos, de instituições, de entidades. Foi onde eu mais produzi, onde eu mais publiquei na vida. Eu saí por razões de saúde e, depois de lecionar 48 anos, achei que já estava bom. É muito tempo. Continuei com alguns orientandos, tem três ainda e até agosto estarei com eles. Eu acho que trocar de orientador durante o processo é complicado, salvo, se a pessoa é acompanhada por meio de orientação coletiva. Em função de mais uma revolução que teve em Piracicaba, eu acabei assumindo a coordenação da pós, um período muito difícil. Difícil por um lado, porque queriam nos cortar as asas, mas por outro, foi um período muito marcante, porque os professores foram dispensados, voltando do almoço ao ligar seu computador tinha um aviso importante, a pessoa abria e dizia "você está sendo dispensado". 148 professores foram dispensados. Eu já tinha sido eleito para tomar posse em janeiro, me disseram assuma e que em conjunto levaríamos tal situação. Os professores dispensados recorreram à justiça, porque a nova reitoria não havia cumprido o que estava regimentalmente disposto. A universidade teve que readmitir, mas muitos não quiseram mais ser readmitidos. Começa aí, então, uma outra fase, chegam professores novos e a cultura do curso se altera, porque as relações já eram outras, mudanças muito bruscas. Então eu vivi mudanças, mas isso é da vida, é do ser humano, temos que enfrentar. Nós, quando iniciávamos o curso lá em Piracicaba, no primeiro dia, reuníamos todos os alunos e trazíamos alguns que já tinham terminado o curso e perguntávamos para eles: 'valeu a pena ter feito o mestrado?' 'Valeu a pena ter feito o doutorado?' E a pessoa respondia. Então, se vocês me perguntassem, eu diria: 'valeu a pena'. Eu não tinha pensado no início, lá aos 18 anos, que eu ia ser doutor. Nem sabia

\footnotetext{
13 Professor na UNISO.

14 Professor da UFSCAR.
} 
que existia doutor, para mim doutor era médico ou advogado, eu não tinha ideia. $\mathrm{Na}$ minha cidade somos os primeiros [doutores], sem ser médico, de vez em quando sai até no jornal, lugar pequeno, então fica conhecido.

\section{Qual sua mensagem para os doutorandos no Brasil?}

Professor Cleiton de Oliveira: Eu acho que vale a pena. Quando eu me sentia muito desanimado, eu falava: não vou conseguir fazer a dissertação de mestrado. Eu não vou conseguir fazer doutorado. Aí eu pensava: Mas quantos já fizeram, não é? Então, antes de vocês, milhares já fizeram, outros tantos desanimaram, desistiram. Então, é possível ser doutor. Vocês devem conhecer vários. Exige leitura. Exige uma curiosidade. O professor falou? Anotem, vão procurar. Citou um autor? Procurem quem é, pesquisem. Hoje aqui, vários foram citados e é preciso que se tenha essa curiosidade. Hoje temos uma grande facilidade que não tinha no meu tempo que é a internet. Tem revistas na internet, tem um mundo. No nosso tempo não existia isso, tinha que esperar ser publicado um livro e ter acesso a esse livro. Tínhamos que ir pesquisar nas bibliotecas das grandes universidades, na USP, biblioteca central. A internet trouxe essa grande facilidade, o acesso a revistas, a livros etc., no entanto, traz também um grande risco que é o plágio. Assim como é fácil plagiar, também é fácil descobrir o plágio. Temos que ter responsabilidade, tem casos e casos que a gente descobre. Esse é o tempo presente, é a novidade. Também nos trouxe mais trabalho, recebo sexta-feira à noite, sábado, demandas que antes se concentravam no dia e horário de trabalho presencial. Fazemos orientação por meio virtual ou até mesmo o orientando na sexta-feira à noite encaminha para o orientador seu texto com 30 páginas e na segunda, pergunta: 'o senhor já leu?' [risos]. Tempo presente com seus desafios.

\section{Adolfo-Ignacio Calderón}

Doutor em Ciências Sociais pela Pontifícia Universidade Católica de São Paulo com Pós-doutorado em Ciências da Educação na Universidade de Coimbra. É professor titular do Programa de Pós-Graduação em Educação da Pontifícia Universidade Católica de Campinas (PUC-CAMPINAS), Bolsista de Produtividade em Pesquisa do Conselho Nacional de Desenvolvimento Científico e Tecnológico (CNPq). Líder do GRAPSE - Grupo de Avaliação, Políticas e Sistemas Educacionais, cadastrado junto ao Diretório dos Grupos de Pesquisa no Brasil do CNPq. E-mail: professoradolfocalderon@gmail.com 


\section{Rafael Fernando da Costa}

Doutor em Educação pelo Programa de Pós-graduação da Pontifícia Universidade Católica de Campinas (PUC-CAMPINAS). Mestre em Educação pela PUCCampinas na área de formação de professores. Possui graduação em Ciências Sociais pela PUC-Campinas, sendo bolsista do Programa Institucional de Bolsas de Iniciação Científica (PIBIC) do Conselho Nacional de Desenvolvimento Científico e Tecnológico (CNPq). Atualmente, faz parte do grupo de pesquisa Formação e Trabalho Docente da linha de pesquisa Formação de Professores e Práticas Pedagógicas do Programa de Pós-graduação da PUC-Campinas. E-mail: rafaelich3@gmail.com

\section{Marco Wandercil}

Cientista Social e Doutor em Educação pela Pontifícia Universidade Católica de Campinas (PUC-CAMPINAS). É professor nas Faculdades Santa Lúcia (MogiMirim - São Paulo) e de Casa Branca (Casa Branca - São Paulo). Membro do GRAPSE - Grupo de Avaliação, Políticas e Sistemas Educacionais, cadastrado junto ao Diretório dos Grupos de Pesquisa no Brasil do Conselho Nacional de Desenvolvimento Científico e Tecnológico (CNPq). Avaliador de Cursos de Graduação do Banco de Avaliadores (BASis) do Sistema Nacional de Avaliação da Educação Superior (SINAES), Instituto Nacional de Estudos e Pesquisas Educacionais Anísio Teixeira, Ministério da Educação. E-mail: marco. wandercil@gmail.com 